\title{
Real Time Person Independent Communication Between Dumb and Blind Person Using Sign and Text Detection
}

\author{
Rajesh Thakare ${ }^{{ }^{*}}$, Sandeep Kakde ${ }^{2}$ and Pavitha U S ${ }^{3}$ \\ ${ }^{1,2}$ Electronics Engineering Department, Yeshwantrao Chavan College of Engineering, Nagpur \\ 3Department of Electronics and Communication Engineering, M S Ramaiah \\ Institute of Technology, Bangalore, India
}

\section{ABSTRACT}

Primary mode of communication is speech by which information can transfer. But hearing-impaired people are not able to communicate with the world. In this paper, low cost prototype model is developed to bridge communication gap for disable people like deaf, dumb and blind. Dump person uses sign language and blind person uses voice, both gives output in text and audio form. System uses atmega-32 as microcontroller, video recording module and flex sensor for developing communication between deaf and dumb with Blind person. For those persons who bothered to express their feelings due to their lack of ability, this device will helpful for them.

KEY WORDS: FLEX SENSOR, ATMEGA32, VIDEO RECORDING, TEXT DETECTION.

\section{INTRODUCTION}

Being a part of society, physically disabled person communication is important. Communication is the only way available for human beings to express their thoughts, feelings, emotions. But there are some disabilities in which it is quite difficult to express feelings by speaking or by hearing. Since in our society there are peoples who are having hearing, speaking and vision loss. Help these persons so that they will not face such difficulties in future. They can able to express their emotions without any trouble. It is not necessary that communicating members belong to same disability. This device can be used by peoples have any difficulty among deaf, dumb and blind or it can be used by normal people, if they want to do a trail of the system. The low cost system

\section{ARTICLE INFORMATION}

*Corresponding Author: rdt2909@gmail.com

Received 18th Oct 2020 Accepted after revision 28th Dec 2020

Print ISSN: 0974-6455 Online ISSN: 2321-4007 CODEN: BBRCBA

Thomson Reuters ISI Web of Science Clarivate Analytics USA and Crossref Indexed Journal

\section{Clarivate
Analytics}

NAAS Journal Score 2020 (4.31)

A Society of Science and Nature Publication,

Bhopal India 2020. All rights reserved.

Online Contents Available at: http//www.bbrc.in/

Doi: $h$ ttp://dx.doi.org/10.21786/bbrc/13.14/70 which uses lesser components to recognise alphabets, space, help and clear gesture. By considering all possible ways, if the person is speaking and hearing impaired, he will use the flex sensor to express his emotions, which is displayed as well as spoken out, so the other person might have any of the disability though he is blind, or same community, they can identify talks through LCD or Speaker. Similarly, if the person is speaking impaired as well as blind he can use flex or voice input. In future, we will focus on community, blind as well as deaf, since this person cannot visualize and are hearing impaired, it will be quite difficult for them to handle the system.

2. Related Work: A system is proposed by the author, in which the gesture recognition is done by detecting the skin colour segmentation and feature extraction. The recognised gesture is then converted in speech output [ $R$. R. Itkarkar ,2013]. One more appearance based technique is derived in which various possible ways are developed to deal with different gestures [Matheesha Fernando ,2013]. The glove maps the orientation of the hand and fingers with the help of bend sensors, Hall Effect sensors, and an accelerometer [Vishal Bhame,2014]. The Virtual Talk Module which is a handy module which facilitates easy user communication for mute/deaf people. The module communicates satisfactorily by recognizing the gestures

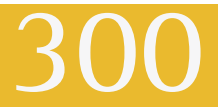


and converting it in words/phrases [Vikram Sharma ,2013]. The comparative study of free hand tracking and glove hand tracking is presented. Video is captured of continuous hand movement and from recorded video frame gesture is detected [D.Mazumdar,2013].Maximum work is carried over appearance based method, many times the recognition is not correct, so there is chance that wrong message can deliver. Hence taking an idea from the developed system, we are designing a new device which will give best results and prove helpful to disabled person.

2.1 Problems Related to System implementation: The voice recognition V3 module has much accuracy. So the voice must match to the pre stored database of voice. The V3 module first check the accent of pronunciation then matching is done. If the pronounced word has same accent then output is produced through speaker as well as on LCD. The flex sensors are very sensitive. According to American Sign Language (ASL) we can show 26 alphabets on single hand. But this thing is not possible by using just a flex sensor. We must use more sensors to achieve the things according to ASL.

2.2 Training and Testing: The training to the microcontroller is to be done using Atmel studio 6.0 version. The training to voice recognition module is given using access port software.APR33A3 is having modes in it so by switching the mode to record we can save the voices in the module and by switching it to play mode we can test it.

3 System Implementation: Figure 1 shows the block diagram representation for real time implementation of system. The system has two inputs flex sensor and microphone via voice recognition module V3 for deaf, dumb and blind person respectively. The inputs are fed to microcontroller Atmega32.The output Microcontroller connected to Video recording and playback module APR33A3 to speaker in audio format and also onLCD display. The components used in the system is described below.

Figure 1: System representation using block Diagram

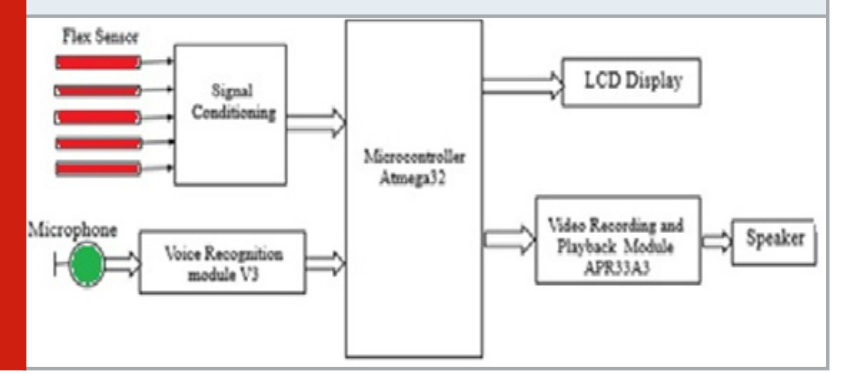

3.1. Microcontroller At-mega32: This microcontroller chip is of AVR family is used to process the input signal for producing an output. The main work of the microcontroller is decision making. By comparing the sign with stored values, it will produce the output in display mode and audio mode. At-mega32 is provided with four different ports- Port A, B, C and D, in which
Port A is ADC port pin 40-33 is assigned to ADC0-ADC7. The flex sensors are connected to Port A. The LCD Display is connected at Port $\mathrm{B}$, voice recording and playback module is connected at port $\mathrm{D}$. The second microcontroller is having other input that is voice recognition V3 Module at port C. Both the microcontroller is connected to each other. The designed system is developed for deaf and dumb person in which flex sensor is used to feed the input. System uses 5 flex sensors on one hand, one flex on each finger.

3.2. Flex Sensor: The Flex sensor is used in our system for feeding input given by deaf and dumb person. Flex sensor is having conductive ink layer printed on the flexible base. When Flex bend, the conductive layer stretched and thus extends resulting in reduced cross section. This reduced cross section and increased length results in increase in resistance. The resistance value when flex is straight is $11.2 \mathrm{~K} \Omega$ and when it is bent the flex resistance is $19.3 \mathrm{~K} \Omega$.Flex sensor of length 4.5 "provide focusing of 90 degree and 180 degree bending. Deaf, dumb person use sign language to express their emotion, the hand expression is there talk. Hence, the sensor connected on fingers of their hand measures the movement of flex and describes a specific alphabet for that gesture.

Figure 2: Port connection of microcontroller

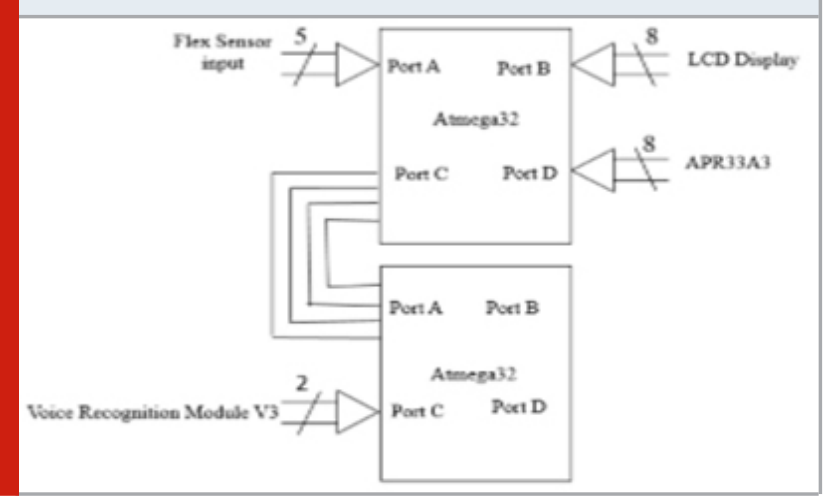

3.3. Voice Recognition Module V3: This module we are using to provide voice input. It is having around 97\% accuracy. It is programmed using RS232 cable connector using access port software. It has $5^{*} 3$ group, that is 3 groups are available which store 5 voice. Selecting one group, People who are blind or have very low vision can benefit from using the technology to convey words and here the device recite to them.

\subsection{Voice recording and playback module APR33A3:}

This module is to generate the audio of our gesture. This module is having 8 channels which store one voice at each channel, by setting it to recording mode. To playback the sound set the module on play mode. The recorded voice is played back of that respective channel. To record another message on the same channel where already message exist then the previous gets replaced with this new one. The hardware implementation of the system is shown in figure 3 . The flex sensors are connected to comparator IC along with $50 \mathrm{~K} \Omega$ resistor 
(blue coloured in diagram). The reference voltage is set using potentiometer which is also $50 \mathrm{~K} \Omega$. The output from comparator is connected to microcontroller pin 33-37. The APR33A3 module (Blue coloured) is connected to pin 14-21. The speaker is connected to APR33A3. The LCD display is connected to pin 1-8 of microcontroller.

Figure 3: Hardware Implementation of Desired System

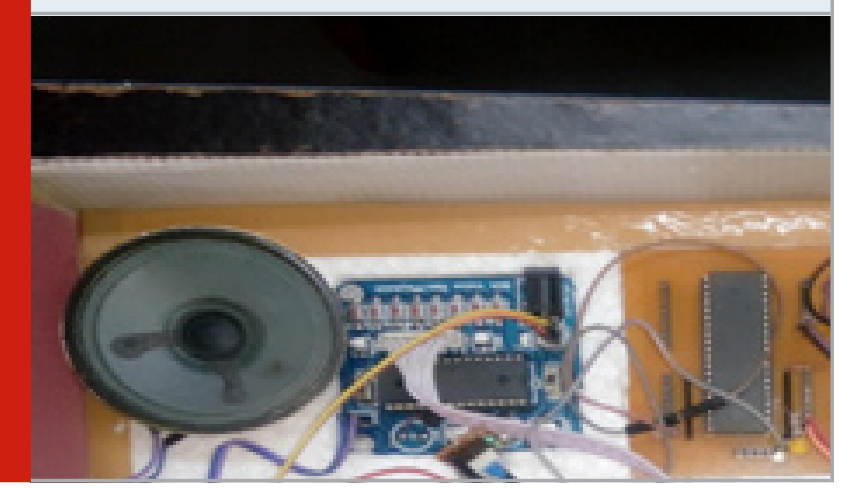

The voice recognition V3 module (Black coloured) is connected to another microcontroller. The microphone is attached to the module itself. The outputs from the desired system for deaf and dumb person using flex sensor is carried out for alphabets A, C, E, I, L, M, O, T, U, $\mathrm{W}, \mathrm{Y}$ and help gesture, space gesture and clear gesture.

\section{RESULTS AND DISCUSSION}

These gesture and their respective outputs are shown in Table 1 below. The voice recognition systems will recognition the word 'WELCOME'. But it will recognize the word when $u$ will speak out in the same accent. The additional gesture for indication of HELP is added in the system. If any emergency occurs the deaf, dumb person has to do that gesture, the pre-stored voice for help is spoken out from speaker. The American Sign Language is one handed language. All the 26 alphabets are indicated on the same hand. But for that purpose we need more sensors. For orientation, there is need of accelerometer sensor. For prototype model few alphabets have implemented in this system.

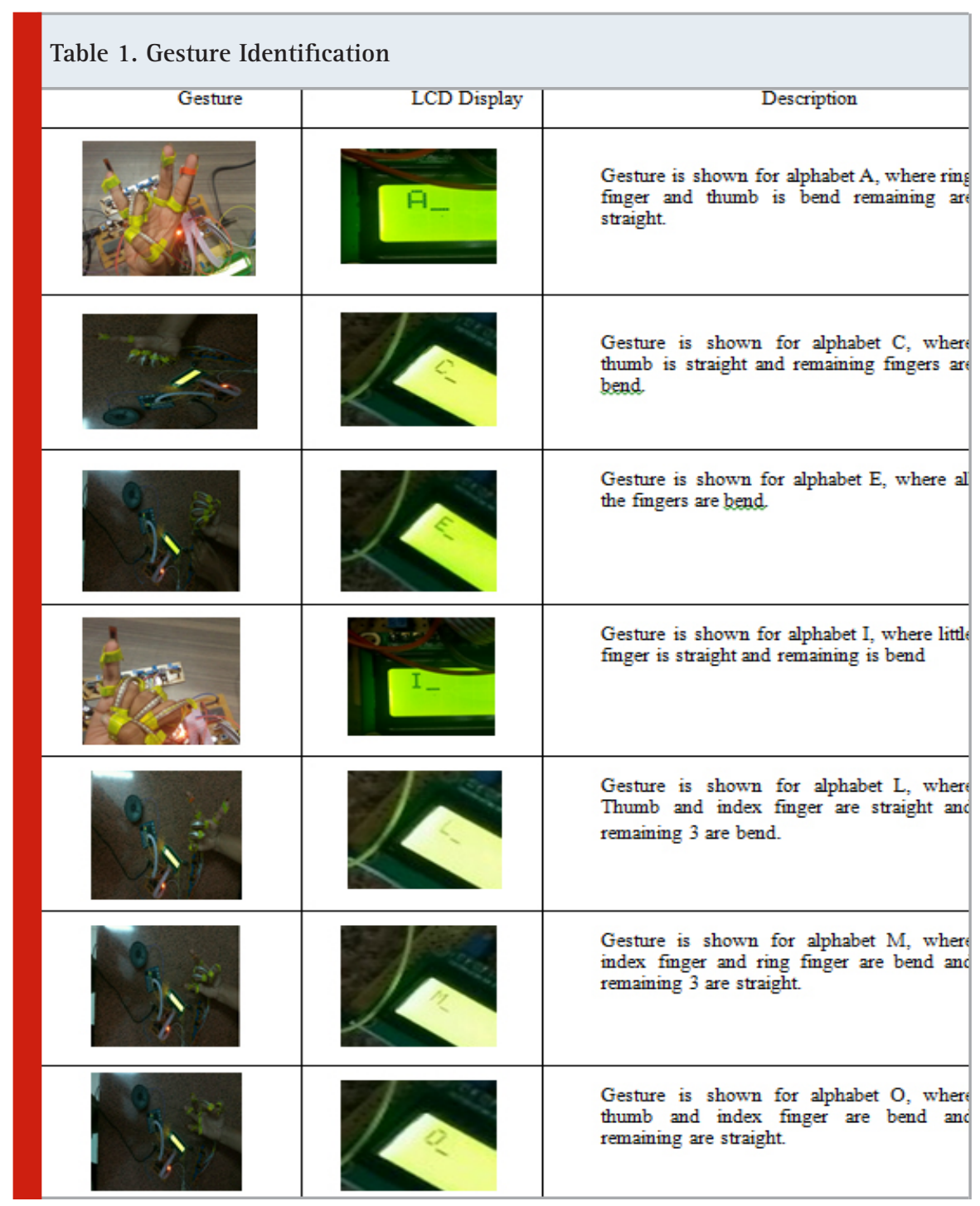




\section{Continue Table}

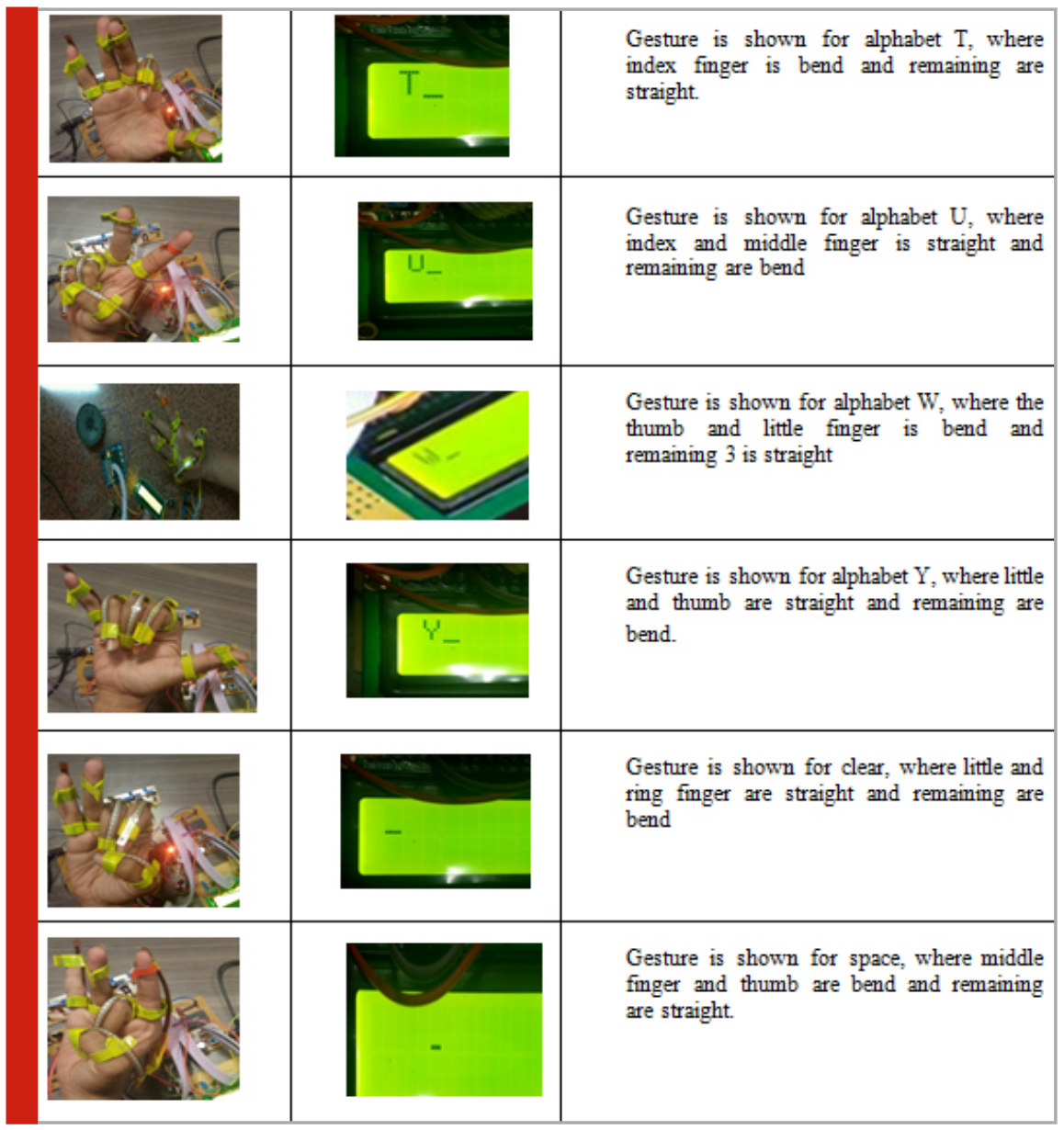

Figure 4: Gesture for Help

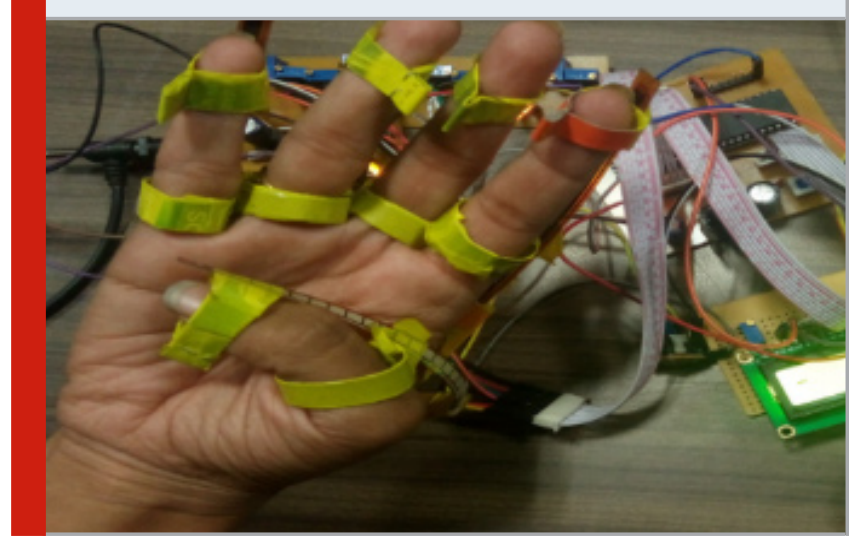

CONCLUSION

The prototype is user independent system developed represents one of the way to design a low cost effective system which requires less power to operate. Anyone can use this system having knowledge of sign language. Since Text format is available so if any correction is needed, then this deaf, dumb person can re-correct it. Efficient working module is designed using easily available components in market. Since we are not working on $\mathrm{ADC}$, the system will not require much time to recognize the gesture. The deaf, dumb person communicate using flex sensor. Whereas the blind user has the flexibility, he can use the flex senor or voice recognition V3 module for giving input. If any problem occurs to any user then an extra gesture for HELP is added in it. The module APR33A3 can stores 8 voices, just to develop the demo version of the system. Using programming and using many more alphabets, digits and sentences, the system can be designed at high level.

This system will become universally applicable if it is developed with same components and with more additional features. The fabrication cost for single is quite more, but to implement it at large scale then, the cost needed can be minimized. This developed module can be used in the disabled persons orphanage's, where these deaf, dumb and blind can actually work on this project and get help from it to establish easy communication. The deaf, dumb can also learn the alphabets using our system since display version is available. In future, we will focus on community, blind as well as deaf, since this person cannot visualize and are hearing impaired, it will be quite difficult for them to handle the system. Using Braille Lippi, this learning facility can be designed in the same system for blind community.

\section{REFERENCES}

Itkarkar, R.R. and Nandi, A.V., 2013, July. Hand gesture to speech conversion using Matlab. In 2013 Fourth International Conference on Computing, Communications and Networking Technologies 
(ICCCNT) (pp. 1-4). IEEE.

Fernando, M. and Wijayanayaka, J., 2013, December. Low cost approach for real time sign language recognition. In 2013 IEEE 8th International Conference on Industrial and Information Systems (pp. 637-642). IEEE.

Bhame, V., Sreemathy, R. and Dhumal, H., 2014, September. Vision based hand gesture recognition using eccentric approach for human computer interaction. In 2014 International Conference on Advances in Computing, Communications and Informatics (ICACCI) (pp. 949-953). IEEE.

Sharma, V., Kumar, V., Masaguppi, S.C., Suma, M.N. and Ambika, D.R., 2013, April. Virtual talk for deaf, mute, blind and normal humans. In 2013 Texas Instruments India Educators' Conference (pp. 316-320). IEEE.

Mazumdar, D., Talukdar, A.K. and Sarma, K.K., 2013, September. Gloved and free hand tracking based hand gesture recognition. In 2013 1st International Conference on Emerging Trends and Applications in Computer Science (pp. 197-202). IEEE..

Gayathri, A. and Sasi Kumar, A., 2017. Sign Language Recognition for Deaf and Dumb People Using Android Environment. INTERNATIONAL JOURNAL OF CURRENT
ENGINEERING AND SCIENTIFIC RESEARCH (IJCESR), 4.

Ingole, A., Ambatkar, S. and Kakde, S., 2015, April. Implementation of health-care monitoring system using Raspberry Pi. In 2015 International Conference on Communications and Signal Processing (ICCSP) (pp. 1083-1086). IEEE.

Bhat, S., Amruthesh, M. and Ashik, C., 2015. Translating Indian Sign Language to text and voice messages using flex sensors. International Journal of Advanced Research in Computer and Communication Engineering, 4(5).

Verma, P., Shimi, S.L. and Priyadarshani, R., 2015. Design of Communication Interpreter for Deaf and Dumb Person. International Journal of Science and Research, 4(1).

Dinesh, S., 2015. Talking Glove-A Boon for the Deaf, Dumb and Physically Challenged. International Journal of Advanced Research in Electronics and Communication Engineering, 4(5), pp.1366-1369.

Patil, N., Ambatkar, S. and Kakde, S., 2017, April. IoT based smart surveillance security system using raspberry Pi. In 2017 International Conference on Communication and Signal Processing (ICCSP) (pp. 0344-0348). IEEE. 